\title{
The Impact of Chinese and Western Cultural Differences on English Translation
}

\author{
Zhang Jing \\ Wuhan Technology and Business University, School of Economics and Business Foreign Language, \\ Hubei, China, 430065
}

Keywords: Chinese and Western cultures; differences; English translation; influence

Abstract: On the surface, English translation is a kind of inter-linguistic translation, which carries huge cultural information and historical background behind the language. Language and culture are interdependent and mutually reinforcing, and translation is the way to transform the two languages. There are still great cultural differences between China and the West. The differences between religious culture, historical culture, customs and regional culture in the process of Chinese-English translation will have a direct impact on the quality of translation. This paper mainly elaborates the influencing factors of cultural differences between China and the West on English translation, as well as the effective measures taken to eliminate the influence of cultural differences, with a view to promoting cooperation and exchanges between the two sides.

Culture has a wide range of meanings. Different countries have different customs, customs, ways of behavior, literature, art and religious history. Language is a vital part of national culture. Language contains the development history and many traditional customs of the country. Chinese and English have their own cultural characteristics and history. Therefore, there are many problems in the daily translation process of the two languages. They often translate different meanings from the original sentence, which is the reflection of cultural differences on the translation between English and Chinese. Ring. Therefore, only by understanding the similarities and differences of English and Chinese language styles and historical and cultural differences, can we effectively reduce such cultural differences and better carry out language translation and communication activities.

\section{Linkages between Cultural Differences and English Translation}

The essence of translation is not only the expression of sentence meaning, but also the translation of connotation on the basis of the original culture. Therefore, in the process of translation, if we can not understand the culture of other countries, it is easy to translate the sentence meaning under the influence of our own culture or can only be superficially translated. Besides not expressing the connotation of the culture of that country, we also lose the essence of translation. Therefore, in the whole process of English translation, translators must combine the local social background and folk and religious culture, and on the basis of a thorough understanding of the culture of the country, translate it, so as to retain the original connotation of the culture of the country. At the same time, as 
a bridge of cultural communication between the two countries, translators need to grasp the presentation of cultural differences between the two countries on the basis of their own culture in order to make the two peoples accept it.

\section{The Impact of Chinese and Western Cultural Differences on English Translation}

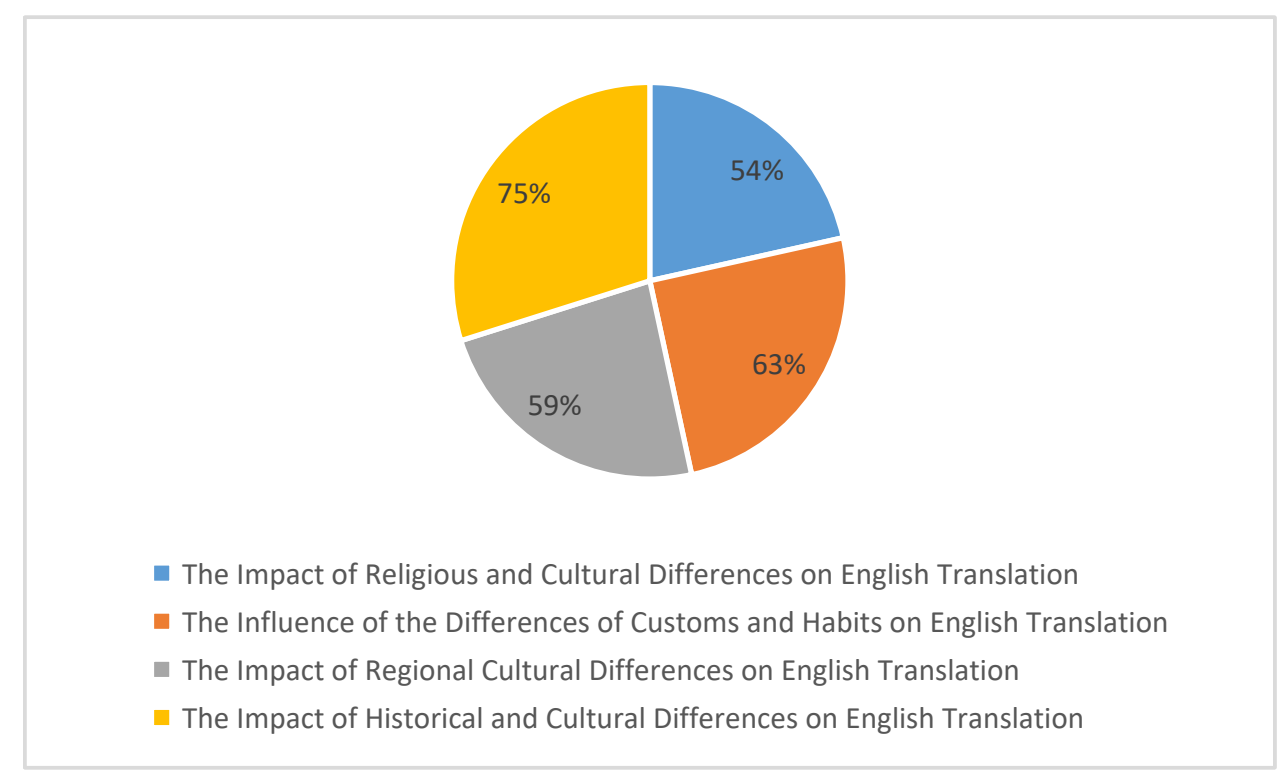

Figure 1. The Impact of Chinese and Western Cultural Differences on English Translation

As shown in figure 1, a detailed analysis is presented below.

\subsection{The Impact of Religious and Cultural Differences on English Translation}

Christian culture is the main body of Western culture. Most of the existing western cultures are derived from Christian culture. To fully understand western culture, we need to learn and understand Christian culture first, so as to understand more western cultural traditions and historical origins, and thus better carry out translation work. In many vocabularies, English and Chinese have their corresponding vocabulary, but because of the differences in history and culture, they have different meanings.For example, dragon is translated into dragon in English. Although it literally means dragon, the meanings expressed in the two languages are quite different. The dragon robes of Chinese emperors are embroidered with five-clawed golden dragons. In China, the dragon has always been the symbol of emperor, sacred and noble. The Chinese dragon is the totem of the Chinese nation, the symbol of Chinese culture and the cultural heritage of the Chinese nation. In the West, dragon stands for a seven-headed reptile monster, which is a synonym for ominous, evil, monster and ferocity. Therefore, when translating, we should pay special attention to this kind of words in order to avoid mistakes.

\subsection{The Influence of the Differences of Customs and Habits on English Translation}

Every nation has its own customs and habits. Customs and habits not only represent the lifestyle of a nation or region, but also are influenced by the living environment, culture and education, political policy, economy and religion. Language, as the most distinctive culture of a nation, records of these bits and pieces will largely reflect customs and habits, and the commonly used idioms can reflect national customs and customs. For example, the English often say "all at sea", people who 
do not know English customs and habits will certainly translate into "at sea", but this is a common English idiom, which means that they are at a loss.

\subsection{The Impact of Regional Cultural Differences on English Translation}

Each region's regional culture has its own unique characteristics. Regional culture is a kind of culture formed slowly in different geographical environment, regional conditions and natural environment. It can represent the way and attitude of people in this region towards many things, even the character of most people. Because of geographical location, ocean currents and surrounding mountains, China's easterly wind is warmer and the westerly wind is chilly; Britain's is warm and the easterly wind is piercing, which is contrary to China's situation. Therefore, annotations and explanations must be made when translating this aspect.

\subsection{The Impact of Historical and Cultural Differences on English Translation}

History and culture represent a nation's glorious history and past, including all the experiences of the nation, including wars, changes in political government, changes in the earth's crust and many other events. Language as the most distinctive national culture, every trace of history and culture is left in idioms and spoken language.

There is an old saying: Every road leads to Rome, which reflects how large the Roman Empire was. At that time, the Romans conquered half the world, including Britain. So there are many idioms in English that record the situation at that time, such as all roads lead to Rome just mentioned, and Rome was not built in a day. Day; Do in Rome as Rome do; and so on. These records the history of British invasion by the Roman Empire. If the translator is not familiar with this history, there will be many problems and confusions in translation.

\section{Effective Measures to Eliminate the Impact of Cultural Differences}

The cultural differences between China and the West exist objectively. Due to the differences in regions, religions, customs and other aspects, the understanding of vocabulary between Chinese and English is different. However, in order to avoid errors caused by cultural differences in the process of translation, relevant measures are needed to reduce the impact and promote the communication between the two languages. As shown in figure 2.

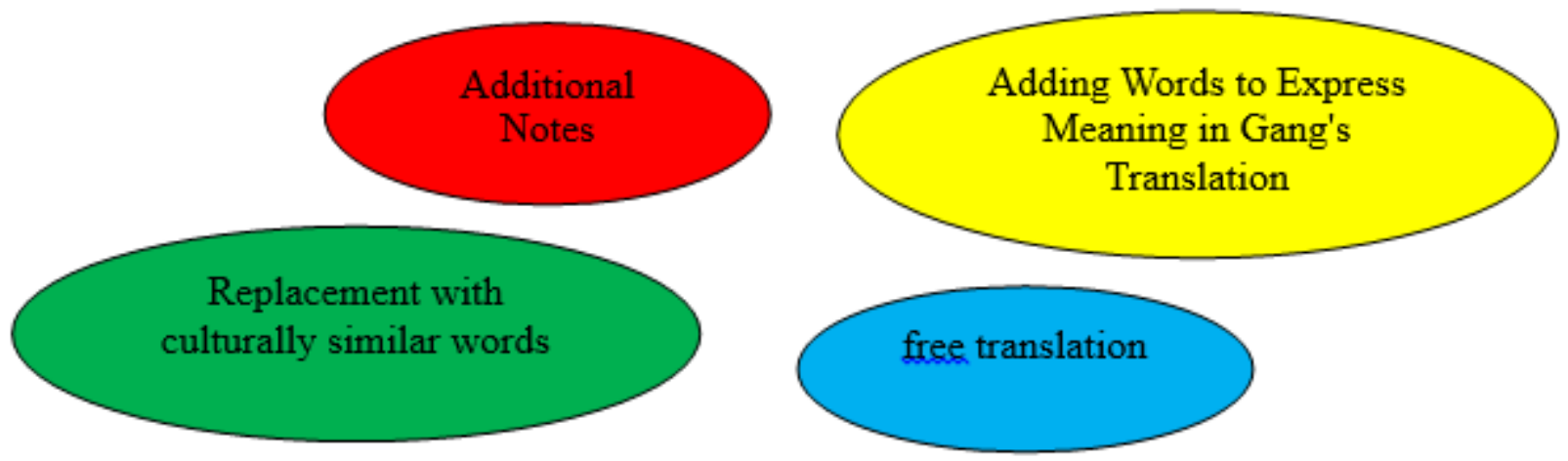

Figure 2.Effective Measures to Eliminate the Impact of Cultural Differences

\subsection{Additional Notes}

In the process of translation, some words and meanings are peculiar to the language of a certain 
nationality or a certain place, and must be annotated in order to make people understand. For example, the idiom mentioned in the preceding article, "Dongs hi Effectiveness", if it is simply deduced into "Bung Shah Imitates Hashish", it will be difficult to understand this idiom correctly. People who don't know Chinese culture will not know who Dongs hi is and what his effects are. But if annotations are added to explain the identities of Dongs hi and Hashish, the meanings of idioms will be clear at a glance, for example: Shantung Imitates His shah (His shah was a famous beauty in the ancient Kingdom of Yue. Bung Shah was an ugly girl who tried to imitates her way).

\subsection{Adding Words to Express Meaning in Gang's Translation}

Sometimes, literal translation is usually used in order to preserve the cultural color of the original text, but for non-native people with cultural differences, it greatly increases the difficulty of reading. Therefore, it is necessary for the translator to add necessary words, phrases and clauses on the basis of the original vocabulary, so that the grammatical and linguistic forms of the translation conform to the habits of the translation, and keep the same with the original in terms of cultural background and word association. This is called additive translation. For example, “It was Friday and soon they'd go out and get drunk"If it is translated literally as "Friday arrives, they will go and get drunk immediately", they will not be able to express their connotations to the reader, but will let the reader produce "Why do you want to drink on Friday?" Questions. Fridays are used in the original text because Fridays are payday in Britain. When translating Fridays into English, the reader can easily understand them and put them into context.

\subsection{Replacement with culturally similar words}

Due to the cultural differences between the two countries, in the process of Chinese-English translation, it is not directly used to translate words with the same or similar meanings, but to replace words or sentences with similar meanings. In short, it is to retain the original meaning of the original sentence by using words with similar cultural meanings or words with prickles in the translated text. For example, He sank down on the chair with his face in his hands.In Chinese, the word "sank" means "sinking, sinking", but here it is translated as "falling". By changing the meaning of words, the reader's comprehension can be enhanced. For example, "The old man said,'They said his father was a fisherman. Maybe he was as poor as we are."' The second "was" in translation needs to be added to mean "used to be as poor as us" in order to facilitate misreading and understanding.

\subsection{Free translation}

For some words, their meanings are profound. If they are translated literally, it is difficult to express the profound connotations of their culture. But if they are replaced by other words, it may lead to misunderstanding. In this case, it is necessary to use free translation. Free translation is to translate according to the main idea of the original text, instead of word-by-word translation (difference and literal translation), which is usually used when the original and the Italian embody great cultural differences. For example, the idiom "When the old man on the frontier lost his mare, who could have guessed it was blessed disguise" is literally translated as "When the old man on the frontier lost his mare?" .

\section{Conclusion}

Generally speaking, although there are many similarities or similarities in the expressions 
between Chinese and English, their individualized features are still highlighted in the process of practical application. It is precisely because of the differences in the expression of Ding Temple that confusion and misunderstanding will arise in the process of translation and increase the difficulty of misunderstanding. Therefore, in the process of English translation, in order to eliminate this influence, it is necessary to give full consideration to cultural factors. Through the understanding of local religion, literature and art, political culture, historical geography, local conditions and human feelings, we should stand at the level of culture and nationality to understand them. Only in this way can we minimize the cultural differences in English translation. Furthermore, it can better understand the meaning of the original text, ensure the maximum consistency between the translation and the original text, meet people's reading needs and strengthen cultural exchanges.

\section{References}

[1] Li Ja. Exploring the influence of cultural differences between China and the West on English translation [J]. Reading Abstracts, 2017 (14): 131-132.

[2] Jorge. Based on the influence of cultural differences between China and the West on English translation [J]. Youth, 2017 (32): 89.

[3] Wu Jannie. On the influence of cultural differences between China and the West on English translation [J]. Reading Abstracts, 2016 (21): 56.

[4] Wang Ding. Translation and Intercultural Interpretation [J]. Chinese Translation, 2014 (2): 5-14.

[5] Deng Die. A study on the conflict between English and Chinese translation based on Chinese and Western cultural backgrounds [J]. Journal of North China University of Water Resources and Hydro power, 2015 (10): 138-140. 